\title{
Evaluating the efficacy and safety of the myrtle (Myrtus communis) in treatment and prognosis of patients suspected to novel coronavirus disease (COVID-19): study protocol for a randomized controlled trial
}

Maryam Azimi ${ }^{1,2}$ and Fatemeh Sadat Hasheminasab ${ }^{3^{*}}$ (D)

\begin{abstract}
Background: Since December 2019, the outbreak of coronavirus pneumonia was observed in China and quickly propagate in all of the world. Nowadays, many trials are underway on this disease in which the efficacy of various therapeutic remedies including chemical or natural agents as well as different non-pharmacological methods such as acupuncture are evaluated. This study aims at investigating the effect of $M$. communis fruit for treatment of COVID-19 disease.
\end{abstract}

Methods: We are performing an open-label randomized controlled trial on outpatients clinically suspected to COVID-19 disease in the age range of 18-65 years old with mild to moderate symptoms and without respiratory distress. Patients in both groups ( $M$. communis and control) receive conventional therapy, but those in $M$. communis group get $M$. communis preparation in addition to conventional therapy. Intervention will continue for 5 days and the study outcomes including clinical status as well as mortality rate and adverse effects will be measured up to 14 days.

Discussion: The protocol describes the design of an ongoing randomized controlled trial to establish the evidence for the usage of water extract of M. communis fruit in clinically suspected COVID-19 disease and identify any safety concerns.

Trial registration: The trial has been registered at the Iranian Registry of Clinical Trials website under the code IRCT20180923041093N3 on March 28th, 2020 (https://www.irct.ir/trial/46721). The results will be disseminated through manuscript publications and presentations to scientific meetings.

Keywords: COVID-19, Myrtle, Herb, Persian medicine, M. communis

\section{Background}

The outbreak of the pneumonia caused by the novel coronavirus (COVID-19) was first observed in Wuhan, Hubei province, China, in December 2019 and quickly spread all over the country, and then almost all

\footnotetext{
* Correspondence: hashemifa67@gmail.com; hasheminasab@zaums.ac.ir ${ }^{3}$ Pharmacology Research Center, Zahedan University of Medical Sciences (ZaUMS), Zahedan, Iran

Full list of author information is available at the end of the article
}

throughout the world, it formed a global concern as a pandemic $[1,2]$. The infection caused by the novel coronavirus has a wide range from asymptomatic infectious to mild upper respiratory tract disease which may lead to severe pneumonia and even death $[3,4]$. At the onset of clinical symptoms, most patients have such complaints as fever, cough, shortness of breath, muscular pain, and fatigue. Some patients also experience loss of taste and smell, headaches, or diarrhea. Patients with

(c) The Author(s). 2020 Open Access This article is licensed under a Creative Commons Attribution 4.0 International License, which permits use, sharing, adaptation, distribution and reproduction in any medium or format, as long as you give appropriate credit to the original author(s) and the source, provide a link to the Creative Commons licence, and indicate if changes were made. The images or other third party material in this article are included in the article's Creative Commons licence, unless indicated otherwise in a credit line to the material. If material is not included in the article's Creative Commons licence and your intended use is not permitted by statutory regulation or exceeds the permitted use, you will need to obtain permission directly from the copyright holder. To view a copy of this licence, visit http://creativecommons.org/licenses/by/4.0/. The Creative Commons Public Domain Dedication waiver (http://creativecommons.org/publicdomain/zero/1.0/) applies to the data made available in this article, unless otherwise stated in a credit line to the data. 
mild symptoms may have only fever and fatigue, whereas in severe cases, patients experience shortness of breath, hypoxia, and acute respiratory distress syndrome, which may include severe metabolic acidosis, coagulation disorders, and septic shock. The mortality rate varies in different age groups and under different conditions and underlying diseases, but it is generally not high compared to similar diseases; nevertheless, due to the high probability of transmission of this disease, mortality and economic costs are significant [5-7].

Healers with different therapeutic approaches, including classic medicine, herbal medicine, acupuncture, Chinese medicine, and Persian medicine have intent to find a solution to cure or lessen the signs and symptoms of this contagious disease [7, 8]. Exploring the clinical trials registered on different World Health Organization Primary Registries proved a notable attention to complementary and alternative medicine (CAM) for controlling the novel coronavirus pneumonia [7]. Previously, considerable studies had been designated in the field of CAM for prevention, treatment, and rehabilitation of Severe acute respiratory syndrome (SARS) and influenza [9].

The aqueous extract of $M$. communis fruit in combination with sugar as a $M$. communis syrup is an ancient remedy for pneumonia recommended in Persian medicine manuscripts. Heart tonic, lung tonic, antitussive, and anti-diarrhea activities are some of the properties mentioned for $M$. communis [10, 11]. Recent studies demonstrated the antioxidant, anti-inflammatory, antiviral, and anti-microbial properties of this herb. Therefore, considering the pharmacological activities of $M$. communis in addition to traditional approval, this remedy seems to be a promising candidate for performing clinical trials and assessing its efficacy on controlling this disease.

\section{Methods/design}

\section{Study objectives and hypothesis}

The main purpose of the proposed trial is to determine whether $M$. communis preparation can accelerate the healing process of patients clinically suspected to COVID-19 pneumonia and decrease the hospital admission and other related complications.

Primary hypothesis: taking M. communis fruit preparation in the first days of clinical suspicion to COVID-19 will subside the sign and symptoms of the disease, as well as decrease the respiratory distress and enhance the well-being.

\section{Public involvement}

The present trial is designed against the uncertainties about the value of applying alternative therapy and herbal medicine for alleviating the symptoms and promoting the prognosis of the mentioned disease. This issue is a popular subject raised by both people and health professionals involving the current pandemic.

\section{Ethical aspects}

The protocol of this study is approved by the Local Medical Ethics Committee of Kerman University of Medical Sciences under the approval code IR.KMU.REC.1399.015; it is also registered at the Iranian Registry of Clinical Trials website under the code IRCT20180923041093N3. This study will be conducted in accordance with the guidelines of Declaration of Helsinki (2008 revision). The procedure will be explained to the patients complying with the inclusion criteria, and each participant will voluntarily sign an informed written consent.

\section{Confidentiality}

Data and source documents will be archived for the purposes of any need for monitoring or inspection by the Ethics Committee. The researchers are only allowed to publish the general and group results of this research without mentioning patients' name and details. The Research Ethics Committee can access patients' information to monitor their rights.

\section{Patients recruitment}

Patients clinically suspected to the COVID-19 pneumonia are considered and enrolled as suspected cases if they meet either an epidemiological history and two clinical manifestations or three clinical manifestations without epidemiological history. Other inclusion criteria include the age range of 18-65 years old, absence of respiratory distress, and candidate for outpatient care and home isolation. They would be eligible if they do not have exclusion criteria including pregnancy, lactation, allergy to $M$. communis, diabetes, hypertension, hepatic disorder, and renal disorder. Exclusion criteria further covered recent consumption of herbal drugs. The criteria for discontinuing the trial are allergy or any other adverse effects to $M$. communis, applying other herbs during the project, and irregular consumption of $M$. communis preparation.

\section{Study design}

This open-label randomized controlled clinical trial will be conducted to determine the effect of $M$. communis preparation on subjects clinically suspected to COVID19 pneumonia. In this trial, the allocation ratio was considered 1:1.

\section{Study setting}

This study will be conducted in the referral clinic of Afzalipour Hospital affiliated to Kerman University of Medical Sciences, Kerman, southeastern Iran. A trained general physician will visit the patients. Next, in case of 
clinical diagnosis of COVID-19 pneumonia, they will be introduced to researchers. Finally, patients who meet eligibility criteria will be invited to the study. Patients' recruitment has been started from April 2, 2020.

\section{Randomization and allocation}

All eligible patients will be randomly allocated to intervention and control groups. A biostatistician generated a randomization list via a blocked randomization method (non-stratified, four patients in each block) using Microsoft Excel $^{\circ}$ software. A secretary enrolls participants to intervention groups via sequentially numbered opaque envelopes.

\section{Intervention}

The researchers obtain written informed consent from the participants, then they are randomly divided into intervention (M. communis) and control groups. Patients in both groups are permitted to take only conventional treatment which are indicated in the fifth edition of the novel coronavirus pneumonia guideline of the Iranian Ministry of Health and Medical Education. According to this guideline, the allowed medication for outpatients who are not high risk is supportive care such as acetaminophen, and for those who are high risk is hydroxyl chloroquin sulfate or chloroquine phosphate. It should be noted that high-risk patients are excluded from this study. Patients in the intervention group should take $M$. communis preparation in addition to classic medication. So, they received packets containing $M$. communis fruit and sugar. On a daily basis, they should gently boil the contents of a pack containing $10 \mathrm{~g}$ of $M$. communis fruit and $10 \mathrm{~g}$ of sugar in 3 glasses of water until 2 glasses of the liquid remain; next, they should percolate it and drink 1 glass in the morning and 1 glass in the evening for 5 days.

Trained assessors collect data and record them in prepared forms. The compliance of the participants will be evaluated via a telephone survey to record the usage of study medication and any side effects. A team from the
Vice-Chancellor for Research monitors the processes. The test schedule and procedures are provided in Table 1.

\section{Ancillary and post-trial care}

Patients are followed up directly for 9 days after the intervention. They can contact the researchers until a month later in case of any presenting adverse effects. Researchers are responsible for providing treatment conditions to eliminate any side effects caused by the intervention.

\section{Outcome measures}

The outcomes will be determined in different time points including $0,1,2,3,4,7$, and 14 days after the intervention, and the primary assessment time will be on the 7th day after the intervention.

The primary outcome and the method of measurement is as follows:

- Cough (severity), via Fisman Cough Severity Score, graded as five points $(0,1,2,3,4)$ varying between 0 (no cough) and 4 (severe cough with chest discomfort) [12]

The secondary outcomes include the following:

- Temperature, via thermometer (centigrade)

- Myalgia, via visual analog scale (VAS) [13]

- Weakness, via VAS

- Cough (frequency), via Fisman Cough Severity Score

- Respiratory rate (the number of breaths per minute)

- Hospital admission (\%)

- Taste and smell disorder (\%)

- Mortality rate (\%)

- Adverse effect

\section{Sample size}

Due to the lack of a similar study, the primary sample size was initially considered to be 70 (35 in each arm)

Table 1 The test schedule and procedures of suspected COVID-19 patients participating the study

\begin{tabular}{|c|c|c|c|c|c|c|c|c|}
\hline \multirow{2}{*}{$\begin{array}{l}\text { Study phase } \\
\text { Study days }\end{array}$} & \multirow{2}{*}{$\begin{array}{l}\text { Screening } \\
\text { Day } 0\end{array}$} & \multicolumn{5}{|c|}{ Randomization/intervention phase } & \multicolumn{2}{|c|}{ Follow-up } \\
\hline & & Day 1 & Day 2 & Day 3 & Day 4 & Day 5 & Day 7 & Day 14 \\
\hline Informed consent & $x$ & & & & & & & \\
\hline Assessing the eligibility & $x$ & & & & & & & \\
\hline Demographics & $x$ & & & & & & & \\
\hline History and Physical examination & $x$ & & & & & & & \\
\hline Assessing the variables & $x$ & $x$ & $x$ & $x$ & $x$ & $x$ & $x$ & $x$ \\
\hline Pulse oximetery & $x$ & & & & & & & \\
\hline Randomization & & $x$ & & & & & & \\
\hline Recording the adverse effect & & & $x$ & $x$ & $x$ & $x$ & & \\
\hline
\end{tabular}


[14]. Then an interim analysis will be done and the final sample size will be calculated with the comparison of parameters (mean \pm standard deviation of cough severity) between the intervention groups on the 7th day after intervention, using the following formula.

$$
n=\frac{\left(Z_{1-\alpha / 2}+Z_{1-\beta}\right)^{2}\left(S_{1}^{2}+S_{2}^{2}\right)}{\left(\mu_{1}-\mu_{2}\right)^{2}}
$$

Type I $(\alpha)$ and type II $(\beta)$ errors will be set at 0.05 and 0.1 , respectively.

If the primary sample size is adequate, the study will be finished, and if it is inadequate, the study will be continued (under the supervision of the ethics committee of Kerman University of Medical Sciences).

\section{Statistical analysis}

Only the data of participants who complete the followup will be considered. Their demographic data including gender and age will compare between the two groups using the chi-square test. To compare the changes in the symptoms experienced by the patients in the two groups at 7 different time points (on enrollment, 1, 2, 3, 4, 7, and 14 days), the repeated measures ANOVA will apply. The independent samples t-test will also be utilized for comparing the changes between the two groups. Differences of groups (M. communis and control) will be reported as mean and $95 \%$ confidence intervals. Thus, the resultant value of $p<0.05$ will be considered significant. The statistical analysis will perform via SPSS 23 .

\section{Definition of end of the study}

The end of study will be the last patient's last visit. However, the Vice-Chancellor for Research and ethics committee of Kerman University of Medical Sciences have supervision on trial and make the final decision to terminate the study.

\section{Data management}

There are no legal, ethical, or security issues related to recording, collection of the data, storage, processing, and dissemination for this trial. We will not generate any sensitive data, and also we will not undersign any confidentiality contract. All data will be archived for up to 10 years after the study.

\section{Potential weakness in study design}

The protocol of this study was conceived when the PCR test was not adequately available for confirming the diagnosis of COVID-19 infection; on the other hand, the placebo-controlled setting can enhance the value of the study. Hence, it can be concluded that another placebocontrolled study on the confirmed COVID-19 patients is required and ethically justifiable.
Lack of monitoring such laboratory data as inflammatory factors, lymphocyte count, and renal and liver function, as well as the lack of following the chest radiography, are the other limitations of this study.

\section{Discussion}

The efficacy, safety, and availability of the treatment are the key factors indicating the success of any drug in being welcomed. Previous successful experiences on the efficacy of herbs of traditional Chinese medicine in managing SARS, middle east respiratory syndrome (MERS), and influenza have resulted in designing various researches on different aspects and capacities of alternative medicine for alleviating COVID-19 disease [8]. The present research will provide evidence as to whether $M$. communis is safe and appropriate for treating COVID19 pneumonia. Myrtus communis, as a potent anti-viral agent, may be useful especially in the early stage of the disease [15]; on the other hand, its anti-inflammatory property can reduce the cytokine storm [16]. The efficacy of this herb on diarrhea has been proved in several researches [17]. In addition, based on the ancient Persian medicine resources, $M$. communis extract can be recommended for pneumonia especially when accompanied by cough and diarrhea [11].

The evaluation of the safety of the plant is very crucial especially in such significant projects as COVID-19 disease. Previous clinical trials on $M$. communis did not mention any serious adverse effects [18]. On the other hand, $M$. communis is used only for 5 days. Therefore, there are no major concerns regarding the possible side effects of a long-term consumption. In addition, the growing trend of this disease, its high costs of treatment and hospitalization, and resource constraints prove the need to explore safe, effective, and inexpensive COVID-19 medications for shortening the disease course and enhancing the prognosis. Hence, an evidence-based clinical trial to evaluate the effectiveness of $M$. communis in treating pneumonia induced by COVID-19 certainly has merit.

Resultantly, we have described a clinical trial for the treatment of COVID-19 pneumonia using M. communis in Kerman, Iran. Moreover, based on the results of this study, we will hold a large-scale clinical trial, with the aim to comprehensively assess the efficacy and safety of M. communis against COVID-19 infection.

\section{Trial status}

The protocol version number is two with revision ID: 137273 and registration date: June 3, 2020. The patient recruitment for this research has begun on April 18, 2020. It is expected to continue till July 30, 2020. Any modification in coordination with the Ethics Committee will be recorded on Iranian registry of clinical trials web-site. 


\section{Acknowledgements}

Not applicable.

\section{Authors' contributions}

FS. H. is the Chief Investigator; she conceived the study, led the proposal protocol development, and wrote the draft of the manuscript. M. A. contributed to study design, development of the proposal, and collecting data. Both authors read and approved the final manuscript

\section{Funding}

The researchers received no financial support for this project.

\section{Availability of data and materials}

The results of this study have the potential for public health applicability. The target audience will be reached through oral presentations, publications, and seminars. The researchers will have to be sure that the participant's privacy is maintained. Data and source documents will be archived for the purposes of any need for monitoring or inspection by the Ethics Committee. At the end of the study, participants will be able to access a copy of the results of the trial from the researchers.

\section{Ethics approval and consent to participate}

The protocol of this study is approved by the Local Medical Ethics Committee of Kerman University of Medical Sciences under the approval code IR.KMU.REC.1399.015. Written, informed consent to participate will be obtained from all participants.

\section{Consent for publication}

Not applicable.

\section{Competing interests}

The authors declare that they have no competing interests.

\section{Author details}

${ }^{1}$ Gastroenterology and Hepatology Research Center, Kerman University of Medical Sciences, Kerman, Iran. ${ }^{2}$ Department of Traditional Medicine, School of Persian Medicine, Kerman University of Medical Sciences, Kerman, Iran. ${ }^{3}$ Pharmacology Research Center, Zahedan University of Medical Sciences (ZaUMS), Zahedan, Iran.

Received: 13 July 2020 Accepted: 18 November 2020

Published online: 26 November 2020

\section{References}

1. Gautret P, Lagier J-C, Parola P, Meddeb L, Mailhe M, Doudier B, et al. Hydroxychloroquine and azithromycin as a treatment of COVID-19: results of an open-label non-randomized clinical trial. Int J Antimicrob Agents. 2020:1(56):105949.

2. Lai C-C, Shih T-P, Ko W-C, Tang H-J, Hsueh P-R. Severe acute respiratory syndrome coronavirus 2 (SARS-CoV-2) and corona virus disease-2019 (COVID-19): the epidemic and the challenges. Int J Antimicrob Agents. 2020; 55(3):105924.

3. Huang C, Wang Y, Li X, Ren L, Zhao J, Hu Y, et al. Clinical features of patients infected with 2019 novel coronavirus in Wuhan, China. Lancet. 2020:395(10223):497-506

4. Wang D, Hu B, Hu C, Zhu F, Liu X, Zhang J, et al. Clinical characteristics of 138 hospitalized patients with 2019 novel coronavirus-infected pneumonia in Wuhan, China. Jama. 2020;323(11):1061-9.

5. Gautier JF, Ravussin Y. A new symptom of COVID-19: loss of taste and smell. Obesity. 2020;28(5):848.

6. Guan W-J, Ni Z-Y, Hu Y, Liang W-H, Ou C-Q, He J-X, et al. Clinical characteristics of 2019 novel coronavirus infection in China. N Engl I Med. 2020:382(18):1708-20.

7. Qiu R, Wei X, Zhao M, Zhong C, Zhao C, Hu J, et al. Outcome reporting from protocols of clinical trials of coronavirus disease 2019 (COVID-19): a review. medRxiv. 2020. https://doi.org/10.1101/2020.03.04.20031401.

8. Cui H-T, Li Y-T, Guo L-Y, Liu X-G, Wang L-S, Jia J-W, et al. Traditional Chinese medicine for treatment of coronavirus disease 2019: a review. Tradit Med Res. 2020;5(2):65-73.

9. Luo H, Q-I T, Y-x S, Liang S-b, Yang M, Robinson N, et al. Can Chinese medicine be used for prevention of corona virus disease 2019 (COVID-19)?
A review of historical classics, research evidence and current prevention programs. Chin J Integr Med. 2020;26(4):243-50.

10. Avicenna H. The canon of medicine (Al-Qanon fi al-Tibb). Beirut: Dar Ihyaa al-Turaath al-Arabi; 2005.

11. al-Nafis I. Al-Shamel fi Sana'at al-Tibbiyah (Arabic). Tehran: Institute of Medical History, Islamic Medicine and Complementary Medicine; 2008.

12. Fisman EZ, Shapira I, Motro M, Pines A, Tenenbaum A. The combined cough frequency/severity scoring: a new approach to cough evaluation in clinical settings. J Med. 2001;32(3-4):181-7.

13. Hasheminasab FS, Hashemi SM, Dehghan A, Sharififar F, Setayesh M, Sasanpour P, et al. Effects of a Plantago ovata-based herbal compound in prevention and treatment of oral mucositis in patients with breast cancer receiving chemotherapy: a double-blind, randomized, controlled crossover trial. J Integr Med. 2020;18(3):214-21.

14. Whitehead AL, Julious $S A$, Cooper $C L$, Campbell MJ. Estimating the sample size for a pilot randomised trial to minimise the overall trial sample size for the external pilot and main trial for a continuous outcome variable. Stat Methods Med Res. 2016;25(3):1057-73.

15. Moradi M-T, Karimi A, Rafieian-Kopaei M, Kheiri S, Saedi-Marghmaleki M. The inhibitory effects of myrtle (Myrtus communis) extract on herpes simplex virus-1 replication in baby hamster kidney cells. J Shahrekord Univ Med Sci. 2011:12(4):54-61.

16. Maxia A, Frau MA, Falconieri D, Karchuli MS, Kasture S. Essential oil of Myrtus communis inhibits inflammation in rats by reducing serum IL-6 and TNF-a. Nat Prod Commun. 2011;6(10):1934578X1100601034.

17. Jabri M-A, Rtibi K, Sakly M, Marzouki L, Sebai H. Role of gastrointestinal motility inhibition and antioxidant properties of myrtle berries (Myrtus communis L.) juice in diarrhea treatment. Biomed Pharmacother. 2016;84: 1937-44.

18. Zohalinezhad ME, Hosseini-Asl MK, Akrami R, Nimrouzi M, Salehi A, Zarshenas $M M$. Myrtus communis $L$. freeze-dried aqueous extract versus omeprazol in gastrointestinal reflux disease: a double-blind randomized controlled clinical trial. J Evid Based Complement Altern Med. 2016;21(1):23-9.

\section{Publisher's Note}

Springer Nature remains neutral with regard to jurisdictional claims in published maps and institutional affiliations.
Ready to submit your research? Choose BMC and benefit from:

- fast, convenient online submission

- thorough peer review by experienced researchers in your field

- rapid publication on acceptance

- support for research data, including large and complex data types

- gold Open Access which fosters wider collaboration and increased citations

- maximum visibility for your research: over $100 \mathrm{M}$ website views per year

At BMC, research is always in progress.

Learn more biomedcentral.com/submissions 